\title{
ORIGINAL ARTICLE Overweight and obesity in Mexican children and adolescents during the last 25 years
}

\author{
S Hernández-Cordero ${ }^{1}$, L Cuevas-Nasu ${ }^{1}$, MC Morales-Ruán ${ }^{1}$, I Méndez-Gómez Humarán ${ }^{2}$, MA Ávila-Arcos ${ }^{1}$ and JA Rivera-Dommarco ${ }^{1}$
}

BACKGROUND/OBJECTIVE: The objective of the study was to provide current estimates of the prevalence and trends of overweight and obesity $(\mathrm{OW}+\mathrm{OB})$ in Mexican children and adolescents.

SUBJECTS/METHODS: Body mass index objectively measured was analyzed for 37147 children and adolescents aged 0-19 years obtained in 2012 as part of the National Health and Nutrition Survey (ENSANUT-2012), a nationally representative sample of the Mexican population. In addition, data from previous National Nutrition Surveys obtained in 1988, 1999 and 2006 were compared with analyze trends over a 24-year period (1988-2012) for children $<5$ years of age and adolescents and over a 13-year period (1999-2012) for school-age children. World Health Organization Child Growth Standard was used to define OW+OB.

RESULTS: In 2012, 33.5\% of children < 5 years of age (both sexes) were at risk of overweight or were overweight (OW); $32 \%$ and $36.9 \%$ of girls and boys $5-11$ years of age were $\mathrm{OW}+\mathrm{OB}$, respectively, and $35.8 \%$ and $34.1 \%$ of female and male adolescents were $\mathrm{OW}+\mathrm{OB}$, respectively. Statistically significant trends were documented for all age groups during the study period. Overall change in the combined prevalence in preschool children was $6.3 \pm 1.0$ percentage points ( $p p ; P<0.001 ; 0.26$ pp per year) in the last 24 years, showing the highest increase between 1988 and 1999, whereas for school-age girls (from 1999 to 2012) and adolescent females (from 1988 to 2012), OW+OB increased across all periods at a declining trend, with an overall change of 0.5 and 1.0 pp per year, respectively. Changes in the prevalence of $\mathrm{OW}+\mathrm{OB}$ were highest among children and adolescents in the lowest quintile of the household living condition index.

CONCLUSIONS: Prevalence of OW+OB among children and adolescents increased significantly during the last 13-24 years. The rate of increase has declined in the last 6 years in all age groups. Changes in prevalence of OW+OB presented here suggest that, in Mexico, the burden of obesity is shifting toward the groups with lower socioeconomic level.

Nutrition \& Diabetes (2017) 7, e247; doi:10.1038/nutd.2016.52; published online 13 March 2017

\section{INTRODUCTION}

Prevalence of overweight (OW) and obesity $(\mathrm{OB})$ in all age groups has increased throughout most countries in recent decades, with childhood OB representing a public health challenge. Worldwide, in 2010 an estimated 42 million children were OW, and 35 million were living in developing countries. ${ }^{1}$

$\mathrm{OB}$ in childhood has immediate consequences on health including hyperlipidemia, hypertension and abnormal glucose tolerance as well as orthopedic, neurological, pulmonary, gastroenterological, endocrine and hepatic disorders, especially when $O B$ is severe. ${ }^{2-4}$ Other consequences of $\mathrm{OB}$ are psychological effects and social stigmatization that obese youth face, which can produce serious consequences for emotional and physical health. ${ }^{4,5}$ There is an established link between $\mathrm{OB}$ during childhood and its persistence into adolescence and adulthood. ${ }^{2} \mathrm{OW}+\mathrm{OB}$ are well-recognized risk factors for noncommunicable diseases in adults, such as hypertension, type 2 diabetes and cardiovascular diseases, among others. ${ }^{3,4}$ It is expected that the increase of childhood $\mathrm{OW}+\mathrm{OB}$ will be followed by the occurrence of chronic diseases at younger ages, with the associated disabilities and early death as well as increased expenses for families and country health systems. ${ }^{4,5}$

The burden of childhood $O B$ on the health system is also undeniable and cannot yet be fully estimated. Health problems will be seen in the next generation of adults as obese children today become obese adults. ${ }^{5}$
In Mexico, data from three national surveys conducted in 1988 1999 and 2006, using the International Obesity Task Force (IOTF) classification system described the upward trends on $\mathrm{OW}$ and $\mathrm{OB}$ in school-age children and adolescents at the national level. ${ }^{6}$

The present paper provides the most recent prevalence estimates of $\mathrm{OW}+\mathrm{OB}$ in Mexican children and adolescents aged 0-19 years using data from the 2012 Mexican National Health and Nutrition Survey and describes trends in OW and $\mathrm{OB}$ in the last 13-24 years, using the World Health Organization Child Growth Standard to define OW and OB.

\section{MATERIALS AND METHODS}

Study population and National Health and Nutrition Survey Prevalence of $\mathrm{OW}+\mathrm{OB}$ was calculated using data from the most recent National Health and Nutrition Survey-2012 (Encuesta Nacional de Salud y Nutrición or ENSANUT-2012 according to its acronym in Spanish). For trend analysis, data from previous National Health and Nutrition Surveys obtained in 1988, 1999, and 2006, along with the 2012 data, were used. ENSANUT-2012 was conducted from October 2011 to May 2012 by the National Institute of Public Health in Mexico. A nationally representative sample of the population was selected using a stratified, multistage probability sample design. The sample is representative at state, regional, and urban and rural levels. Information collected during the ENSANUT-2012 comprises anthropometric data (weight and height, among others). A more detailed description of ENSANUT methods has been published elsewhere.? Informed consent was

\footnotetext{
${ }^{1}$ Centro de Investigación en Nutrición y Salud, Instituto Nacional de Salud Pública, Cuernavaca, Morelos, Mexico and ${ }^{2}$ Centro de Investigación en Matemáticas A.C., Unidad

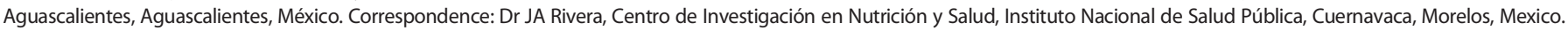
E-mail: jrivera@insp.mx
}

Received 22 March 2016; revised 11 August 2016; accepted 1 November 2016 
obtained from all participants and/or parents or primary caregiver (in case of young children), and the protocol was reviewed and approved by the Institutional Review Board of the National Institute of Public Health.
The study population for the present analyses includes children $<19$ years of age classified according to three different age groups: preschool children ( $<5$ years of age), school-aged children (5-11 years) and

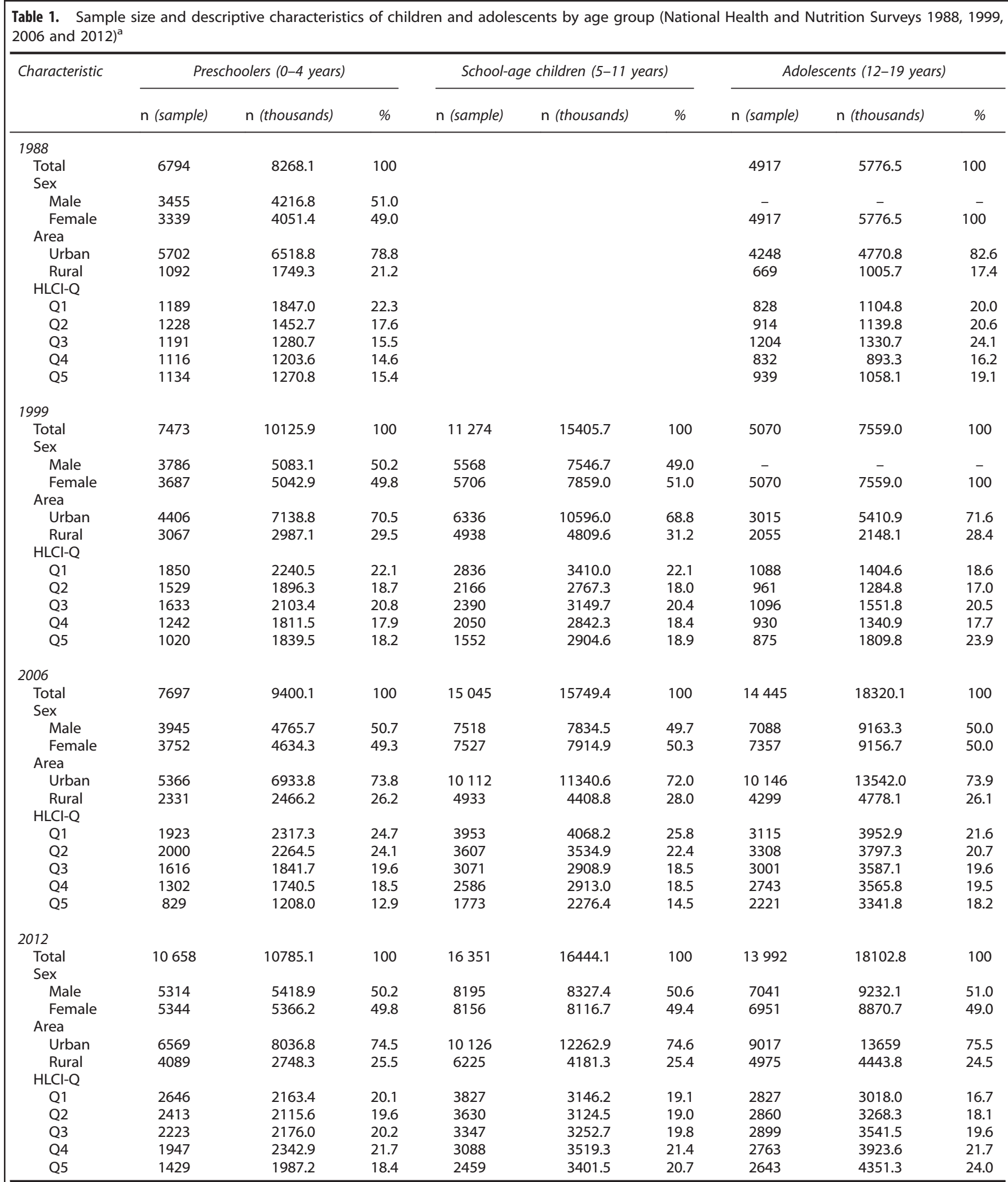

Abbreviations: $\mathrm{HLCl}$, Household Living Condition Index; Q, Quintile. ${ }^{\mathrm{a}}$ Age groups defined as preschoolers: 0-4 years; school-age children: 5-11 years; and adolescents $12-19$ years. 
adolescents (12-19 years). ENSANUT-2012 overall nonresponse rate was $8.7 \%$. A total of $1.25 \%$ of examined children and adolescents had missing data for body mass index (BMI) either because of lack of one or both measurements, implausible data or in the case of pregnancy in adolescent girls. BMI plausible data were considered at a range of -5.0 and +5 s.d., eliminating all those with $\mathrm{BMI}$ values $<10$ or $>38$ for preschool children and school-age children and BMI $<10$ or $>58$ for adolescents. Excluded from the analyses were all cases where $z$-score for height and age was $<-6$ or $>+6$ s.d. For ENSANUT-2012, data for analyses were available for 10658 preschool children, 16351 school-age children and 13992 adolescents (Table 1). Weight and height were measured with the same validated and standardized methods as well as same criteria were used to define plausible anthropometric data for the samples from previous surveys included in the analyses. For previous National Health and Nutrition Surveys of 1999 and 2006, nonresponse rate was $17.6 \%^{8}$ and $0.6 \%,{ }^{9}$ respectively. Unfortunately, there is no information of 1988 survey's nonresponse rate.

\section{Definition of $\mathrm{OW}+\mathrm{OB}$ for all nutritional surveys}

All anthropometric information was measured using standardized techniques and equipment. ${ }^{7} \mathrm{BMI}$ was calculated as weight $(\mathrm{kg})$ divided by height $(\mathrm{m})$ squared. We defined risk of overweight (RO), $\mathrm{OW}$ and $\mathrm{OB}$ among all age groups based on the World Health Organization (WHO) Child Growth Standard for preschool children ${ }^{10}$ and 2007 WHO growth reference for school-age children and adolescents. ${ }^{11}$ For preschool children, the RO category was defined as $z$-score of $\mathrm{BMI}<1$ s.d. and 2 or less s.d. OW and OB was defined as $z$-score +2 s.d. For school-aged children and adolescents, OW was defined as $z$-score of $B M I>1$ s.d. and 2 or less s.d.; $\mathrm{OB}$ as BMI $z$-score $>2$ s.d. ${ }^{9,10}$

Other variables for analysis of ENSANUT-2012

Area of residence was classified according to the number of inhabitants, considering those areas with a population of 2500 or more as urban areas and those with $<2500$ persons as rural areas.

The Household Living Condition Index $(\mathrm{HLCl})$ was used as a proxy of socioeconomic status and was constructed using the principal component analysis. ${ }^{8}$ The $\mathrm{HLCl}$ was constructed considering household characteristics (number of rooms, running water, WC and construction materials) as well as household amenities (washing machine, microwave, stove, television and so on). The first factor was used as the $\mathrm{HLCl}$, explaining $40.5 \%$ of the variance. The index was further divided into quintiles of $\mathrm{HLCl}$ to be considered as categorical variables in the statistical analysis.

\section{Statistical analysis}

For ENSANUT-2012 OW+OB prevalence analysis, we performed frequencies at a national level by age group, sex, area of residence (rural and qurban areas) and $\mathrm{HLCl}$. Trends for OW+OB from the 1988, 1999, 2006 and 2012 surveys were calculated with a standardized proportions difference using the asymptotic normal distribution. ${ }^{12}$ School-age children of both sexes and male adolescents were not measured in 1988; thus, trends were estimated only from 1999 to 2012 in school-age children and for adolescents during the entire 1988-2012 period, but only for females.

To study trends in prevalence of $\mathrm{OW}$ and $\mathrm{OB}$, descriptive analyses were performed using frequencies and their respective $95 \%$ confidence intervals (Cls) stratified at the national level for the four geographic regions, rural and urban areas, and HCLI categories. Multinomial logistic regression models with fixed effects ${ }^{12}$ were used to estimate differences among categories. Prevalence was further divided by age group blocks. Trends for OW+OB from the 1988, 1999 and 2006 surveys were calculated using the standardized difference between proportions. ${ }^{12}$ Due to the fact that the duration of the time periods between surveys differed, in order to compare the prevalence we present the changes as percentage points (pp) and pp per year.

Data were analyzed using the Statistical Program SPSS v. 15.0 with the complex sampling software (SPSS Inc., Chicago, IL, USA) and Stata v.12.1 (Stata Corp., College Station, TX, USA).

\section{RESULTS}

Overweight and obesity: National Health and Nutrition Survey 2012

Overall among children 0-19 years of age, 28.8\% presented either RO (preschool children) or OW, or OB in 2012. Table 2 shows detailed prevalence estimates of $\mathrm{RO}, \mathrm{OW}+\mathrm{OB}$ for preschool children and $\mathrm{OW}$ and $\mathrm{OB}$ for school-age children and adolescents. Results are presented by year of survey, sex (for school-age children and adolescents), area of residence (urban/rural) and $\mathrm{HLCl}$. For comparison purposes we provide the $\mathrm{OW}+\mathrm{OB}$ estimates using the IOTF definition ${ }^{13}$ as Supplementary Material, Supplementary Table 1.

Preschool children. Prevalence of $\mathrm{RO}$ and $\mathrm{OW}+\mathrm{OB}$ was $23.8 \%$ (95\% Cl: $22.5,25.1 \%)$ and $9.7 \%$ (95\% Cl: $8.9,10.6 \%)$, respectively (Table 2). Differences in prevalence by sex were already observed at this early age, with a higher combined prevalence of RO and $\mathrm{OW}+\mathrm{OB}$ in boys $(35.2 \%)$ than in girls $(31.8 \%$; $P<0.001)$. This difference was mainly due to a higher prevalence of RO in boys (25.3\%) than in girls (22.3\%; data not shown). There was no difference in $\mathrm{RO}$ or $\mathrm{OW}+\mathrm{OB}$ either by area of residence or by $\mathrm{HLCl}$.

School-age children. The combined prevalence of OW and OB in boys and girls in this age group was 34.4\% (95\% Cl: 33.3, 35.6\%) with the prevalence of OW being $19.8 \%$ (95\% Cl: $18.8,20.9 \%$; Table 2). The combined prevalence of $O W$ and $O B$ was higher in boys (36.9\%) than in girls (32.0\%); $P<0.001$ (data not shown). The difference in the combined prevalence is due to the higher prevalence of $\mathrm{OB}$ among boys $(17.4 \%, 95 \% \mathrm{Cl}: 16.0,18.8 \%)$ than in girls (11.8\%, 95\% Cl: 10.8, 12.8\%; $P<0.001$; Table 2).

The prevalence of both OW and OB was higher in boys and girls living in urban areas (Table 2). For girls, there was a trend for both $\mathrm{OW}$ and $\mathrm{OB}$, increasing the prevalence as the $\mathrm{HLCl}$ increased. The highest prevalence was found in girls from the highest quintile (OW: $\mathrm{HLCl}$ lowest quintile: 14.9 (95\% Cl: 12.6, 17.5\%)) vs $\mathrm{HLCl}$ highest quintile: $24.8 \%$ (95\% Cl: 21.1, 29.0\%; OB: HLCl lowest quintile: $7.9 \%(95 \% \mathrm{Cl}: 6.2,9.9 \%))$ vs $\mathrm{HLCl}$ highest quintile: 16.2 ( $95 \%$ Cl: $13.6,19.2 \%$; Table 2). For boys, the trend of increasing OW and $\mathrm{OB}$ was more pronounced for the latter (OW: $\mathrm{HLCl}$ lowest quintile $15.7 ; 95 \% \mathrm{Cl}: 13.4,18.3 \%)$ vs $\mathrm{HLCl}$ highest quintile $20.3 \%$ (95\% Cl: 17.2, 23.9\%); OB: HLCI lowest quintile 8.2\% (95\% Cl: 6.3, $10.6 \%$ ) vs $\mathrm{HLCl}$ highest quintile $22.7 \%$ (95\% Cl: 19.2, 26.8\%; Table 2).

Adolescents. Combined prevalence of $\mathrm{OW}$ and $\mathrm{OB}$ in this age group was $35.8 \%$ (95\% Cl: 34.0, 37.6\%) and 34.1\% (95\% Cl: 32.4, $35.8 \%)$ for female and male adolescents, respectively, being slightly higher in females $(P=0.03$; data not shown). The difference in combined prevalence by sex is mainly due to the higher prevalence of $\mathrm{OW}$ in females compared with that in males (23.7 vs 19.6, $P<0.001$, for females and males, respectively; Table 2). Prevalence of both $O W$ and $O B$ was higher in female and male adolescents living in urban areas, whereas the prevalence of $O B$ was higher for adolescents (both male and female) in the highest quintile of the $\mathrm{HLCl}(\mathrm{OB}$ prevalence for females: lowest $\mathrm{HLCl}$ quintile $8.2 \%(95 \% \mathrm{Cl}: 6.5,10.2 \%)$, highest $\mathrm{HLCl}$ quintile 13.2 (95\% Cl: $10.9,15.9 \%)$, males: lowest $\mathrm{HLCl}$ quintile $6.8 \%(4.8,9.5 \%)$, highest $\mathrm{HLCl}$ quintile: $19.4 \%$ (16.4, 22.7\%; Table 2).

\section{Trends of OW and $O B$}

Prevalence of $O W$ and $O B$ in female children and adolescents during the last 24 years. Overall trends of $\mathrm{OW}$ and $\mathrm{OB}$ for girls and female adolescents using the available information are presented in Figure 1. Complete information for the four surveys (1988, 1999, 2006 and 2012) is only available for preschool girls and female adolescents, whereas for school-aged girls there is information from only the 1999-2012 surveys. Prevalence of OW and OB 


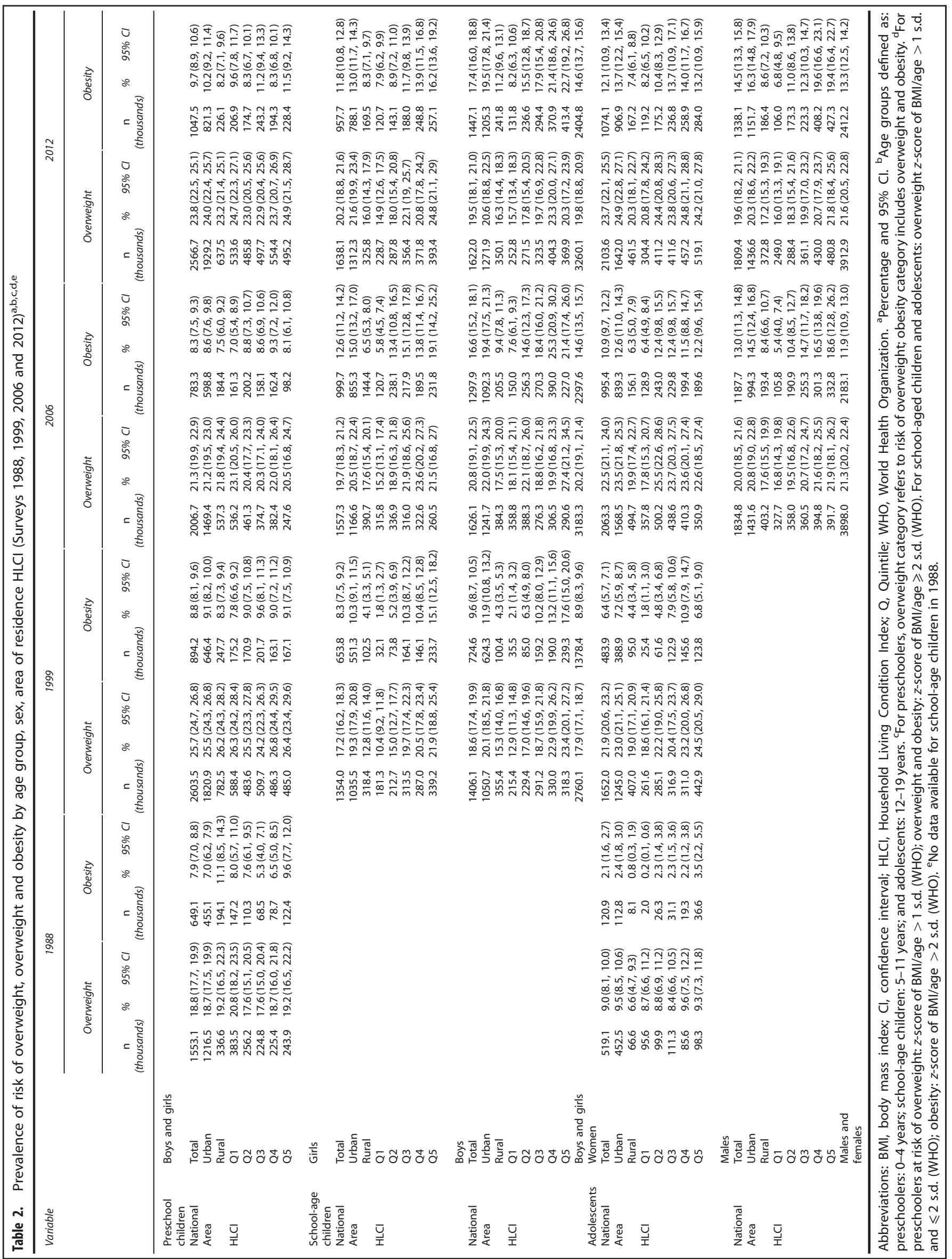


increased in all age groups, with the highest rate of increase among female adolescents followed by school-aged girls.

For preschool girls, there has been a statistically significant increase in all years except between 1999 and 2006, years when the prevalence of $\mathrm{RO}$ and $\mathrm{OW}$ decreased (RO and OW combined prevalence change from 1999 to $2006:-6.1 \pm 1.0$ pp-, $P<0.001$; or $-0.87 \mathrm{pp}$ per year). Overall change in the combined prevalence was $6.3 \pm 1.0 \mathrm{pp}(P<0.001 ; 0.26 \mathrm{pp}$ per year $)$ in the last 24 years, showing the highest increase between 1988 and 1999 (combined prevalence change: $8.4 \pm 1.0 \mathrm{pp}, P<0.001 ; 0.76 \mathrm{pp}$ per year) compared with change from 2006 to 2012 (3.9 \pm 1.0 pp, $P<0.001$; $0.65 \mathrm{pp}$ per year).

For school-aged girls, overall change in the combined prevalence of OW and $O B$ from 1999 to 2012 was $6.2 \pm 0.8 \mathrm{pp}$ $(P<0.001 ; 0.5$ pp per year), demonstrating the highest increase from 1999 to 2006 (6.5 $\pm 0.8 \mathrm{pp}, P<0.001 ; 0.9 \mathrm{pp}$ per year), with no change from 2006 to 2012 (combined prevalence change: $-0.3 \pm 0.7, P=0.65 ;-0.06$ pp per year).

The combined prevalence of $\mathrm{OW}$ and $\mathrm{OB}$ in adolescent females increased $(24.7 \pm 0.8 \mathrm{pp}, P<0.001 ; 1.0 \mathrm{pp}$ per year) from 1988 to 2012, showing the highest and marked increase between 1988 and 1999 (17.2 $\pm 0.9 \mathrm{pp}(P<0.001 ; 1.6 \mathrm{pp}$ per year). The rate of increase began to slow down from 1999 onward; however, there has been a steady increase since then with statistical significance between each survey (combined prevalence change from 1999 to 2006: $5.1 \pm 0.9 \mathrm{pp}, P<0.001 ; 0.7 \mathrm{pp}$ per year); change from 2006 to 2012: $2.4 \pm 0.8 \mathrm{pp}, P=0.002$ (0.4 pp per year).

Trends by age group, $\mathrm{HLCl}$ and area of residence

Preschool children (boys and girls; change from 1988 to 2012): Increase in the combined prevalence of RO and OW in

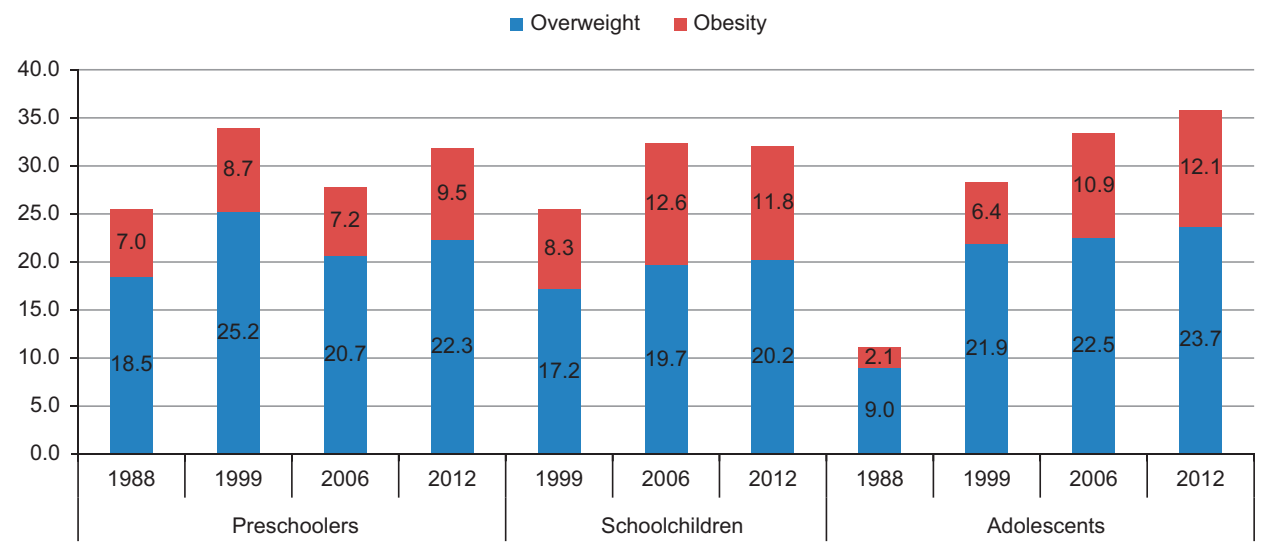

1 Percentage

2 Age groups defined as: Preschool-age children: 0-4 years; School-age children: 5-11 years; and Adolescents: 12-19 years

3 For preschoolers only: Overweight: Includes risk of overweight (RO) category, Obesity: Includes overweight and obesity categories

4 For school-age children, information available only for 1999, 2006, and 2012 surveys

Figure 1. Prevalence of overweight and obesity in girls and female adolescents by age group and survey: $1988-2012 .^{1-4}$

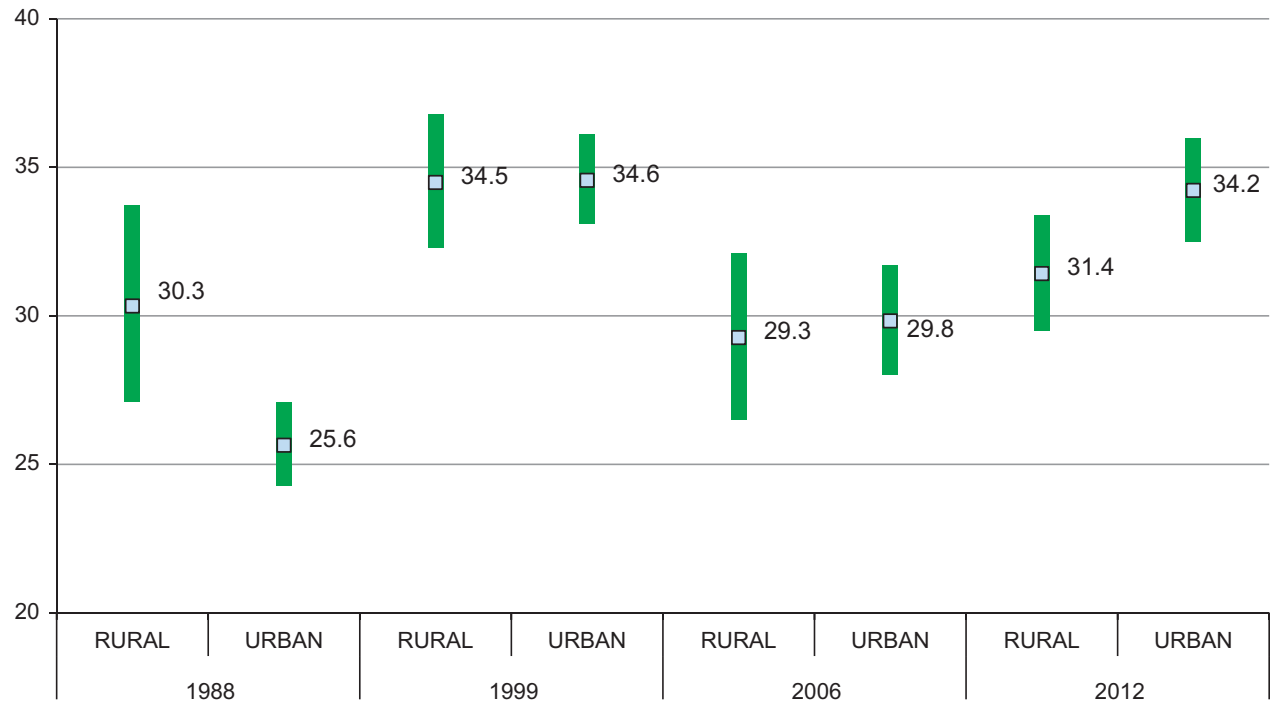

1 Percentage and $95 \%$ CI

2 Age groups defined as: Preschool-age children: 0-4 years

3 Change in prevalence from 1988-2012: Urban: $8.6 \pm 0.8$ pp, $\mathrm{p}<0.001$; Rural: $1.1 \pm 1.6 \mathrm{pp}, \mathrm{p}=0.48$

Figure 2. Combined prevalence of risk of overweight and overweight in preschool-age children (both sexes) by area of residence and year of survey: 1988-2012. ${ }^{1-3}$ 
preschool children occurred at all socioeconomic levels, without demonstrating any difference by $\mathrm{HLCl}$ level (data not shown).

When changes in the combined prevalence of RO and $\mathrm{OW}$ by area of residence were analyzed, the rate of increase was higher among children living in urban areas (1988 prevalence $25.6 \%, 95 \% \mathrm{Cl}$ : 24.3, 27.1\%; 2012 prevalence 34.2, 95\% Cl: 32.5, 36.0\%); change 1988-2012: $8.6 \pm 0.8 \mathrm{pp}, P<0.001$ (0.36 pp per year) than in children living in rural areas (1988 prevalence 30.3, 95\% Cl: 27.1, 33.7\%; 2012 prevalence: $31.4,95 \% \mathrm{Cl}: 29.5,33.4 \%$. Change from 1988 to 2012 was $1.1 \pm 1.6 \mathrm{pp}, P=0.48$ (0.05 pp per year; Figure 2).

School-age children (change from 1999 to 2012): Combined prevalence of $\mathrm{OW}$ and $\mathrm{OB}$ increased in both rural and urban areas from 1999 to 2012. However, the rate of increase was more pronounced in girls living in rural areas (change in prevalence 19992012: rural: $7.5 \pm 1.0$ pp, $P<0.001 ; 0.58$ pp per year); urban: $4.9 \pm 1.0$ pp, $P<0.001$ (0.38 pp per year; Figure 3 ). This trend was not seen among boys in whom the rate of change of combined prevalence of $\mathrm{OW}$ and $\mathrm{OB}$ was similar between area of residence (change in prevalence 1999-2012: rural: $7.9 \pm 1.0 \mathrm{pp}, P<0.001$ (0.60 pp per year); urban: $8.1 \pm 1.0 \mathrm{pp}, P<0.001$ (0.62 pp per year). For both boys and girls, the combined prevalence of $\mathrm{OW}$ and $\mathrm{OB}$ increased at a higher rate in the lower quintiles of the $\mathrm{HLCl}$ compared with the highest quintile (change of prevalence 1999-2012: girls-lowest $\mathrm{HLCl}$ quintile: $10.5 \pm 1.3 \mathrm{pp}, P<0.001$; highest $\mathrm{HLCl}$ quintile: $4.0 \pm 2.3 \mathrm{pp}$,
$P=0.07$; boys-lowest $\mathrm{HLCl}$ quintile: $8.8 \pm 1.4 \mathrm{pp}, P<0.001$; highest $\mathrm{HLCl}$ quintile: 2.0, $P=0.37$; Figure 4).

Female adolescents (change from 1988 to 2012): Combined prevalence of OW and OB increased $16 \pm 1.4$ pp from 1988 to 1999 in rural areas $(P=0.01)$ and $18.4 \pm 1.0$ in urban areas. A smaller increase in the prevalence from 1999 to 2006 was seen in both areas (rural: $2.8 \pm 1.3, P=0.03$; urban: $5.9 \pm 1.1, P=0.01$ ). This rate of increase decreased during the last 6 years but was still on the rise among female adolescents living in urban areas (change in prevalence from 2006 to 2012: 2.6 $\pm 1.0 \mathrm{pp}, P=0.01$; Supplementary Figure $1 \mathrm{~A}$ ).

For $\mathrm{HLCl}$, prevalence of $\mathrm{OW}$ and $\mathrm{OB}$ increased $>11 \mathrm{pp}$ between 1988 and 1999 in all quintiles except the fourth, which showed an increase of $22.3 \pm 1.9 \mathrm{pp}, P=0.01$. From 1999 , the rate of increase at all $\mathrm{HLCl}$ levels decreased and the prevalence for 2006 with respect to 1999 for Q1 and Q2 increased $3.8 \pm 1.6 \mathrm{pp}(P=0.01)$ and $10.8 \pm 1.5 \mathrm{pp}(P=0.01)$, respectively. Between 2006 and 2012, females in Q1 and Q4 showed an increase in the prevalence of OW and $\mathrm{OB}$ of $4.7 \pm 1.6 \mathrm{pp}, P=0.003$ and $3.8 \pm 1.8 \mathrm{pp}, P=0.04$, respectively (Supplementary Figure $1 \mathrm{~B}$ ).

Male adolescents (change from 2006 to 2012): In male adolescents, no changes were observed in the combined prevalence of OW and OB between surveys from 2006 to 2012 (change in prevalence: $1.1 \pm 0.8 \mathrm{pp}, P=0.16$ ), with no difference by area of residence or $\mathrm{HLCl}$ (data not shown).
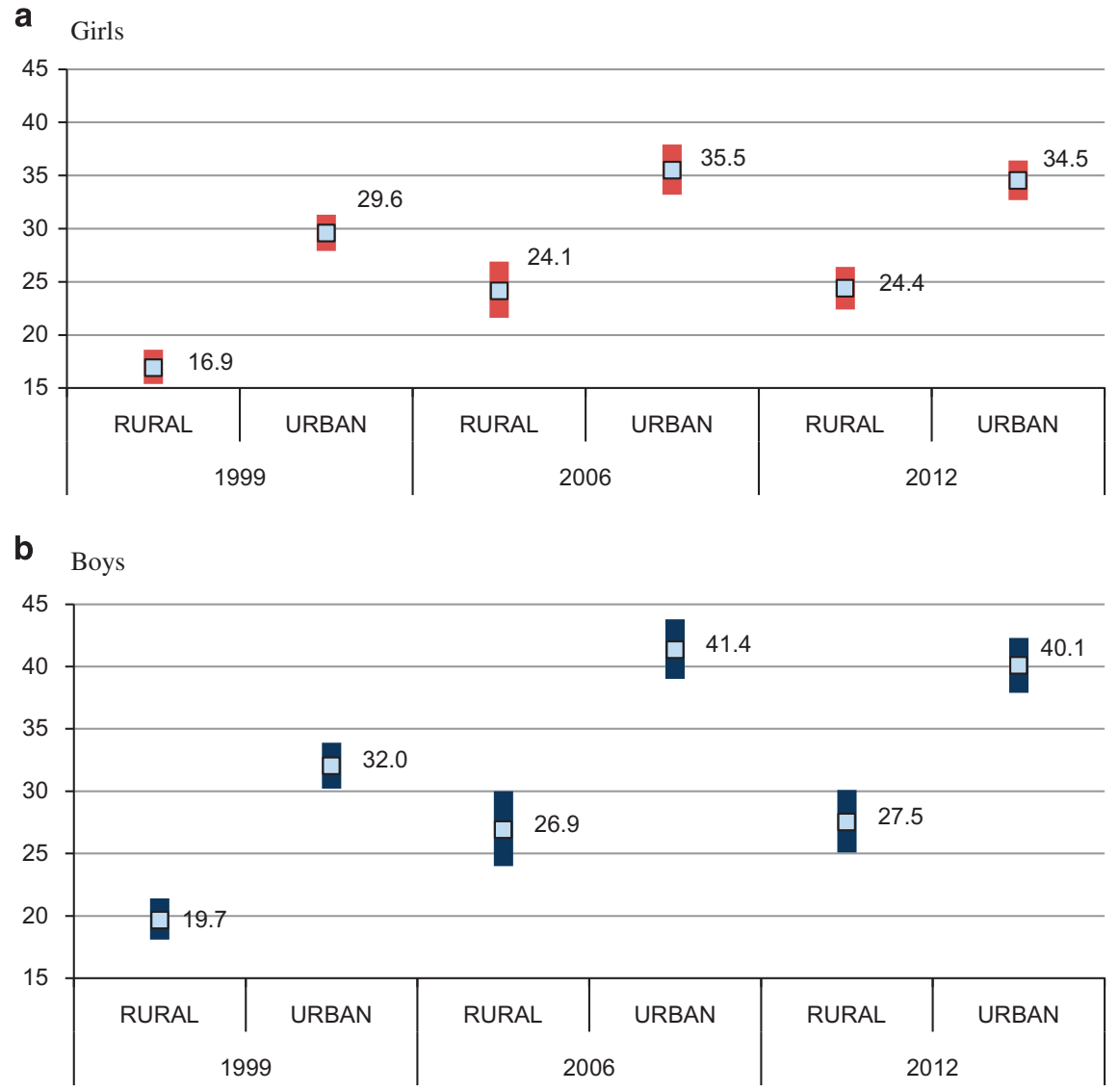

1 Percentage and $95 \% \mathrm{CI}$

2 Age groups defined as: school-age children: 5-11 years

3 Information available for National Health and Nutrition Survey 1999, 2006 and 2012

4 Girls: Change in prevalence from 1999-2012: Urban: $4.9 \pm 1.0$ pp, $p<0.001$; Rural: $7.5 \pm 1.0$ pp, $p<0.001$

5 Boys: Change in prevalence from 1999-2012: Urban: $8.1 \pm 1.0$ pp, $p<0.001$; Rural: $7.9 \pm 1.0$ pp, $p<0.001$

Figure 3. Combined prevalence of overweight and obesity in school-age girls (a) and boys (b) by area of residency and year of survey: 19992012. ${ }^{1-5}$ (a) Girls. (b) Boys. 
$\mathbf{a}_{\text {Girls }}$
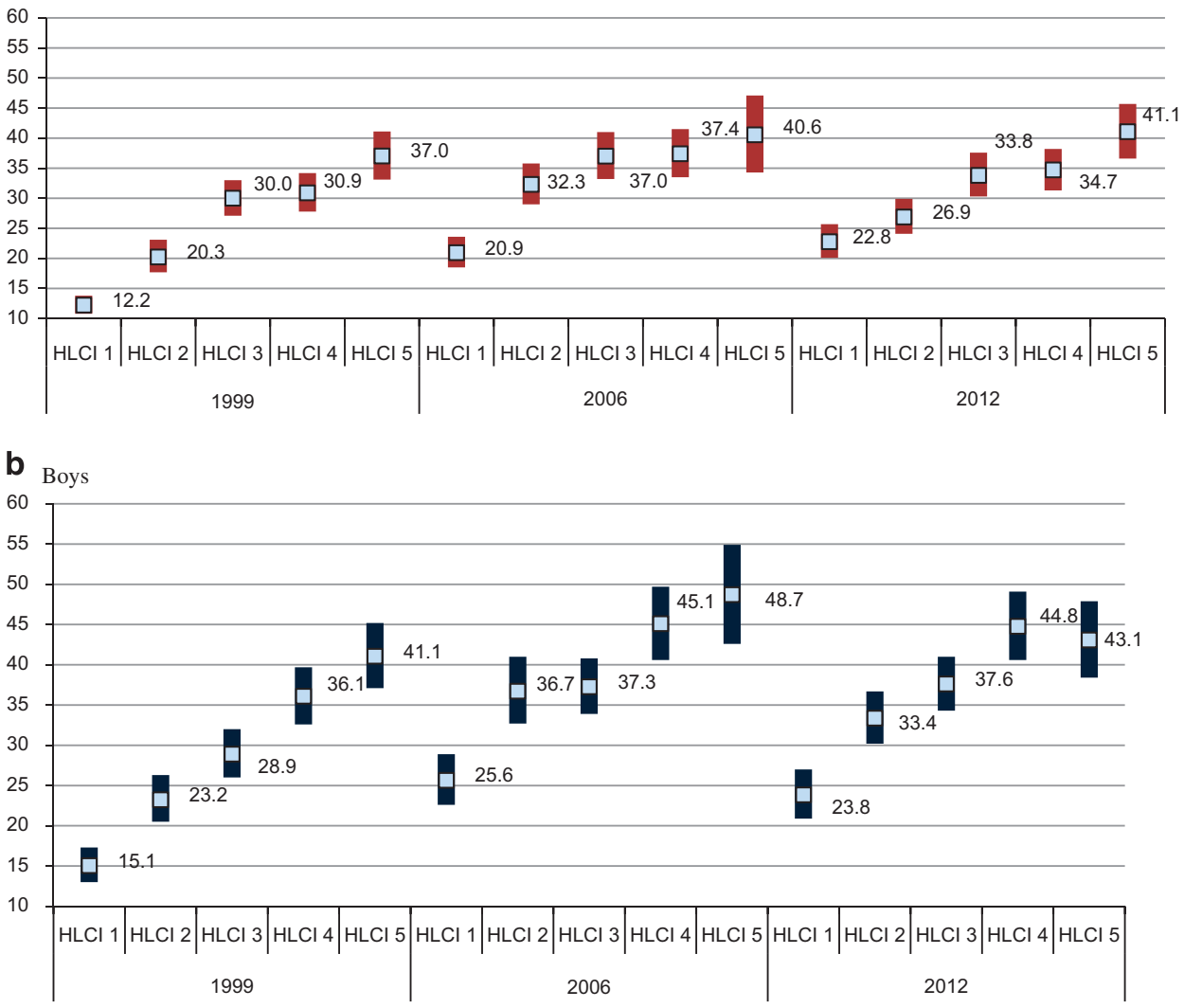

1 Percentage and $95 \% \mathrm{CI}$

2 Age groups defined as: school-age children: 5-11 years

3 Information available for National Health and Nutrition Survey 1999, 2006 and 2012

4 Girls: Change in prevalence from 1999-2012: Lowest HLCI quintile: $10.5 \pm 1.3 \mathrm{pp}, \mathrm{p}<0.001$; Highest HLCI quintile: $4.0 \pm 2.3 \mathrm{pp}, \mathrm{p}=0.07$

5 Boys: change in prevalence from 1999-2012: lowest HLCI quintile: $8.8 \pm 1.4 \mathrm{pp}, \mathrm{p}<0.001$; highest HLCI quintile: $2.0 \pm 2.3 \mathrm{pp}, \mathrm{p}=0.37$

Figure 4. Combined prevalence of overweight and obesity in school-age girls (a) and boys (b) by household living conditions index (HLCl) and year of survey: 1999-2012..$^{1-5}$ (a) Girls. (b) Boys.

\section{DISCUSSION}

Prevalence of $\mathrm{OW}+\mathrm{OB}$ in children and adolescents presented in this article are the most recent estimates in Mexico. Among children and adolescents $<19$ years of age the combined prevalence of OW (and RO for preschool children) and $\mathrm{OB}$ was as high as $28.8 \%$ by 2012 . Combined prevalence of RO and OW $+\mathrm{OB}$ in children < 5 years of age was $33.5 \%$ (RO: $23.8 \%$, OW+OB: 9.7\%) and for school-age children and adolescents was $36.9 \%$ (OW: $19.5 \%$, OB: $17.4 \%$ ) and $35.8 \%$ (OW: $23.7 \%, \mathrm{OB}: 12.1 \%$ ), respectively. By 2012, the highest prevalence was seen among children and adolescents living in urban areas and those from the highest socioeconomic level. In the last 13-24 years, the prevalence of $\mathrm{OW}$ and $\mathrm{OB}$ has increased at the highest rate among female adolescents followed by school-aged girls. Increase in $\mathrm{OW}$ and $\mathrm{OB}$ has been more pronounced among those children from the lowest socioeconomic level in all age groups except for preschool children and those from urban areas for preschool children and adolescents, whereas for school-aged girls, the increase has been higher among those living in rural areas.

When comparing prevalence from other countries using the WHO classification systems (WHO Child Growth Standard for preschool children ${ }^{10}$ and WHO growth reference for school-age children and adolescents WHO 2007,11 childhood prevalence of $\mathrm{OW}$ and $\mathrm{OB}$ in Mexican children is among the highest. A longitudinal study carried out in Cuba demonstrated that the combined prevalence of $\mathrm{RO}$ and $\mathrm{OW}$ in children $<5$ years of age was $17.3 \%$ in $2011^{14}$ and for Colombian preschoolers was $25.2 \%$ in 2005 according to a recent systematic review. ${ }^{15}$ Prevalence of OW and OB in school-age children in Brazilian boys was 34.8\% in 2009 and $18.9 \%$ in 2010 in Colombian children (both sexes), lower than the prevalence in Mexico during the same time (2012), but the prevalence of OW and OB in Chilean children (both sexes) in 1997 was $37.7 \%$, much higher than the prevalence shown in Mexican boys (28.2\%) and girls (25.5\%) during the same year (1999). Prevalence of $\mathrm{OW}+\mathrm{OB}$ in adolescents was relatively low in Colombian adolescents in 2010 (16.7\%) compared with Chile in 2005 (31.0\%), and Mexican males (34.1\%) and females (35.8\%) in 2012. ${ }^{15}$

In 2012, the combined prevalence of OW and OB was higher in preschool and school-age boys than in girls, whereas in adolescents, such prevalence was higher among females than males. Similar sex differences have been reported by Rivera et al. ${ }^{15}$ who found that in those studies reporting data stratified by sex, prevalence of $\mathrm{OW}$ and $\mathrm{OB}$ differed by sex, but the differences varied across age groups. As in our study, in school-age children, more boys were identified as OW or OB than girls in Brazil. On the other hand, in adolescents, unlike in Mexico, the prevalence of OW and $\mathrm{OB}$ was higher among adolescent Brazilian males than in their female counterparts.

Results of the latest Mexican nutritional survey (2012) show that the combined prevalence of $\mathrm{OW}$ and $\mathrm{OB}$ in school-aged children and adolescents was higher among those in the highest quintile of the 
$\mathrm{HLCl}$, a wealth indicator, whereas in preschool children there were no differences according to socioeconomic status indicator. Clustering of OW and $\mathrm{OB}$ by socioeconomic status varies depending upon the study population. There is growing evidence that the distribution of $\mathrm{OW}$ and $\mathrm{OB}$ varies by socioeconomic status and area of residence, which depends on the economic development of the countries. ${ }^{16}$ In some countries such as Russia, ${ }^{17}$ China, ${ }^{17}$ Croatia, $^{18}$ Estonia, ${ }^{18}$ Latvia $^{18}$ and Botswana, ${ }^{19}$ prevalence of OW and OB was higher among more affluent families, similar to our results. In other countries such as the USA ${ }^{16,20}$ and Spain, ${ }^{21}$ the highest rates of OW and OB occur among the most disadvantaged groups.

An important finding of our study is that although the prevalence of $\mathrm{OW}$ and $\mathrm{OB}$ is still higher in the population with higher socioeconomic status, the rate of increase of such prevalence in the last 24 years has been higher in school-aged children and adolescents from the lowest quintile of socioeconomic status. Some explanations for this rapid increase among the poorer strata is supported by the increasing evidence that low-income families tend to consume inexpensive sources of calories due to the relative cost of nutritious foods both in money and preparation time. The source of these calories is usually from energy-dense foods with high-fat content and sugar as well as with poor nutritional quality (low content of vitamins and minerals). ${ }^{20} \mathrm{~A}$ recent analysis in Mexico shows that patterns of intake are different depending on the level of income. The results indicate that the cost per calorie (defined as the amount of money allocated to consume 1 calorie) decreased between 1992 and 2010. Households with lower-income levels make consumption decisions that allow them to obtain a higher level of calories at a lower price, even if this represents a lower dietary quality. ${ }^{22}$ The lower the socioeconomic level, the greater the percentage of purchase and consumption of high-energy-dense foods as well as the lower the purchase and consumption of low-energy-dense foods (mainly fruit and vegetables and low-fat/-sugar foods). ${ }^{22}$ This phenomena has been reported by others, indicating that there is a negative association between income and dietary quality. Thus, as incomes decrease, nutrient-poor energy-dense foods become the best way to provide daily calories at an affordable cost, to the detriment of healthier foods (such as fruits and vegetables), which are more expensive. ${ }^{23}$

There is little information in terms of changes in physical activity among children and adolescents in the last 24 years. There are few studies in Mexican preschool ${ }^{24}$ and school-aged children, ${ }^{25}$ and adolescents. ${ }^{26}$ These studies indicate that low physical activity level and sedentary behavior are common among these age groups. In addition, there is evidence that some of the determinants of low physical activity and sedentary behavior such as urbanization, use of innovation in electronic media (computers, televisions) among others have increased in the Mexican population during the last 20 years. ${ }^{27}$

Another relevant result of this study is the trend of the combined prevalence of OW and OB among preschool girls shown to decrease between 1999 and 2006. As reported previously by Rivera et al., ${ }^{28}$ the observed decrease in prevalence for this group may be the result of the decline in the prevalence of low height for age (stunting) observed during the same time period, which was about $0.86 \mathrm{pp}$ per year.

Finally, it is worth mentioning that among school-age girls there was an apparent plateau in the combined prevalence of OW and OB from 2006 to 2012. This trend has been reported in developed countries like the USA where the prevalence shown in some age groups such as school-age children and adolescents appears to be leveling off ${ }^{29}$ or Denmark where comparison of prevalence from 1998 to 2011 showed that the prevalence rates of OW and OB among Danish infants, children and adolescents were largely still at a plateau with tendencies for a decline among children and adolescents. ${ }^{30}$ Results in the same direction were previously reported in a review of prevalence of $O W$ and $O B$ in nine countries
(Australia, China, England, France, The Netherlands, New Zealand, Sweden, Switzerland and USA), where prevalence of OW and OB was stabilizing. ${ }^{31}$ It may be too early to conclude that this is happening with the prevalence of $\mathrm{OW}$ and $\mathrm{OB}$ in school-age children. Follow-up in regard to this trend with further National Nutrition Surveys will be useful to answer this question. In addition, although Mexico is demonstrating a plateau in OW and $\mathrm{OB}$ in school-age children, a public health crisis remains as a result of the high prevalence of childhood OB.

This paper describes the most recent trends of childhood $O B$ in Mexico. It includes information from different age groups during childhood from four nationally representative surveys during the last 25 years. Mexico is one of the few countries in the Latin American and Caribbean region with repeated National Nutrition Surveys across time, allowing us to explore trends.

Another strength of this study is that we used BMI as the indicator of body fatness. Although the use of BMI as a measure of health risk related to body fat has been criticized, especially in children, ${ }^{32}$ there is evidence that BMI in children is highly correlated with body fat mass and widely used as a valid indirect measurement of adiposity in children. There has been an increased number of growth references expressed as a function of age and sex. ${ }^{31,32}$

An additional strength of the study is the use of the WHO Child Growth Standard for preschool children ${ }^{10}$ and the 2007 WHO growth reference for school-age children and adolescents ${ }^{11}$ with their respective definitions of $\mathrm{OW}$ and $\mathrm{OB}$, thus facilitating comparison with data from other countries.

One limitation of our study is that not all age groups (lack of information in school-age children on the 1988 national survey) and sometimes not both sexes, particularly boys and adolescent males (school-age boys and male adolescents were not measured in 1988 and 2006), have complete information for the analysis of prevalence and trends in the last 25 years, limiting our conclusions for those groups for trends. However, we studied complete trends during the last 25 years for girls and indicated, when necessary, the time frame of trends in cases where information on both sexes was included.

\section{CONCLUSIONS}

Prevalence of childhood $\mathrm{OB}$ in Mexico is one of the highest worldwide. Even though the prevalence shown here indicates a higher prevalence of OW and $\mathrm{OB}$ among those in urban areas and those from more affluent families, changes in prevalence of OW and $\mathrm{OB}$ presented here suggest that, as in other countries, in Mexico the burden of $O B$ is shifting toward groups with a lower socioeconomic level.

\section{CONFLICT OF INTEREST}

The authors declare no conflict of interest.

\section{REFERENCES}

1 Organizacion Mundial de la Salud. Sobrepeso y obesidad infantiles. Organizacion Mundial de la Salud, 2013. Available at http://www.who.int/dietphysicalactivity/ childhood/es (accessed on December 2015)

2 Dietz W. Health consequences of obesity in youth: childhood predictors of adult disease. Pediatrics 1998; 101: 518-525.

3 World Health Organization. Joint WHO/FAO Expert Consultation on Diet, Nutrition and the Prevention of Chronic Disease 2002. WHO Technical Report Series 916: Geneva, 2003.

4 Chizuru N, Uauy R, Kumanyika S, Shetty P. The Joint WHO/FAO Expert Consultation on diet, nutrition and the prevention of chronic diseases: process, product and policy implications. Public Health Nutr 2004; 7: 245-250.

5 Lobstein T, Baur L, Uauy R. Obesity in children and young people: a crisis in public health. Obes Rev 2004; 5: 4-85. 
6 Bonvecchio A, Safdie M, Monterrubio E, Gust T, Villalpando S, Rivera Dommarco J. Overweight and obesity trends in Mexican children 2-18 years of age from 1988 to 2006. Salud Publica Mex 2009; 51: S586-S594.

7 Romero-Martínez M, Shamah T, Franco A, Villalpando S, Cuevas L, Gutiérrez JP et al. Encuesta Nacional de Salud y Nutrición 2012: Diseño y cobertura. Salud Publica Mex 2013; 55: S332-S340.

8 Resano-Pérez E, Méndez-Ramírez I, Shamah-Levy T, Rivera J, Sepúlveda-Amor J. Methods of the National Nutrition Survey 1999. Salud Publica Mex 2003; 45: S558-S564.

9 Olaiz-Fernandez, Rivera-Dommarco J, Shamah Levy T, Rojas R, Villalpando S, Hernández-Ávila M et al. 2006. Encuesta Nacional de Saldud y Nutrición 2006. Instituto Nacional de Salud Pública: Cuernavaca, Morelos, México.

10 World Health Organization. The WHO Child Growth Standards 2007. Available at http://www.who.int/childgrowth/en/ (accessed on May 2013).

11 de Onis M, Onyango A, Borghi E, Siyam A, Nishida C, Lutther C et al. Development of a WHO growth reference for school-aged children and adolescents. Bull World Health Organ 2007; 85: 660-667.

12 Borenstein M, Hedges L, Higgins J, Rothstein H. Introduction to Meta-Analysis. John Wiley and Sons: New York City, USA, 2009.

13 Cole T, Bellizzi M. Establishing a standard definition for child overweight and obesity worldwide: international survey. BMJ 2000; 320: 1-6.

14 Jiménez-Acosta S, Rodríguez-Suárez A. Evolución del sobrepeso en preescolares cubanos en un periodo de diez años. Rev Cubana Pediatr 2013; 85: 428-438.

15 Rivera J, González-Cossío T, Pedraza L, Aburto T, Sánchez T, Martorell R. Childhood and adolescent overweight and obesity in Latin America: a systematic review. Lancet Diabetes Endocrinol 2014; 2: 321-332.

16 Monteiro C, Moura E, Wolney L, Conde W, Popkin B. Socioeconomic status and obesity in adult populations of developing countries: a review. Bull World Health Organ 2004; 82: 940-946.

17 Wang Y. Cross-national comparison of childhood obesity: the epidemic and relationship between obesity and socioeconomic status. Int J Epidemiol 2001; 30: 1129-1136.

18 Due $\mathrm{P}$, Damsgaard $\mathrm{M}$, Rasmussen $\mathrm{M}$, Holstein B, Wardle J, Merlo J et al. Socioeconomic position, macroeconomic environment and overweight among adolescents in 35 countries. Int J Obes 2009; 33: 1084-1093.

19 Wrotniak B, Malete L, Maruapula S, Jackson J, Shaibu S, Ratcliffe S et al. Association between socioeconomic status indicators and obesity in adolescent students in Botswana, an African country in rapid nutrition transition. Pediatr Obes 2012; 7: e9-e13.

20 Drewnowski A. Obesity, diets, and social inequalities. Nutr Rev 2009; 67: S36-S39.

21 Valdés Pizarro J, Royo-Bordonada M. Prevalence of childhood obesity in Spain; National Health Survey 2006-2007. Nutr Hosp 2012; 27: 154-160.

22 Hernández-Licona G, Minor-Campa E, Aranda Balcázar R. Determinantes económicos: evolución del costo de las calorías en México. In: Rivera Dommarco J, Hernández Avila M, Aguilar Salinas C, Vadillo Ortega F, Murayama Rendón C (eds).
Obesidad en México Recomendaciones para una política de Estado. Universidad Nacional Autónoma de México: México, DF, 2012.

23 Uauy R, Albala C, Kain J. Obesity trends in Latin America: transiting from under-to overweight. J Nutr 2001; 131: 893S-899S.

24 Jáuregui A, Villalpando S, Rangel-Baltazar E, Castro-Hernández J, Lara-Zamudio Y, Mendez-Gómez-Humarán I. The physical activity level of Mexican children decreases upon entry to elementary school. Salud Publica Mex 2011; 53: 228-236.

25 Aburto N, Nava F, Bonvecchio A, Safdie M, González-Casanova I, Gust T et al. Physical activity during the school day in public primary schools in Mexico City. Salud Publica Mex 2009; 51: 141-147.

26 Morales-Ruán M, Hernández-Prado B, Gómez-Acosta L, Shamah-Levy T, CuevasNasu L. Obesity, overweight, screen time and physical activity in Mexican adolescents. Salud Publica Mex 2009; 51: S613-S620.

27 Crespo C, Escutía de Domínguez G, Salvo-Domínguez D, Arredondo E. Determinantes de la disminución de actividad física y aumento del sedentarismo. In: Rivera Dommarco J, Hernández Avila M, Aguilar Salinas C, Vadillo Ortega F, Murayama Rendón C (eds). Obesidad en México Recomendaciones para una política de Estado. Universidad Nacional Autónoma de México: México, DF, 2012.

28 Rivera R, Irizarry L, González-de Cossío T. Overview of the nutritional status of the Mexican population in the last two decades. Salud Publica Mex 2009; 51: S646-S656.

29 Ogden C, Carroll M, Kit B, Flegal K. Prevalence of obesity and trends in body mass index among US children and adolescents, 1999-2010. JAMA 2012; 307: 483-490.

30 Schmidt Morgen C, Rokholm B, Sjöberg Brixval C, Schou Andersen C, Geisler Andersen L, Rasmussen $\mathrm{M}$ et al. Trends in prevalence of overweight and obesity in Danish infants, children and adolescents. Are we still on a plateau? PLoS One 2013; 8: e69860.

31 Olds T, Maher C, Zumin S, Péneau S, Lioret S, Castetbon J et al. Evidence that the prevalence of childhood overweight is plateauing: data from nine countries. Int $J$ Pediatr Obes 2011; 6: 342-360.

32 Freedman D, Wang J, Ogden C, Thornton J, Mei Z, Pierson R et al. The prediction of body fatness by BMI and skinfold thicknesses among children and adolescents. Ann Hum Biol 2007; 34: 183-194.

This work is licensed under a Creative Commons Attribution 4.0 International License. The images or other third party material in this article are included in the article's Creative Commons license, unless indicated otherwise in the credit line; if the material is not included under the Creative Commons license, users will need to obtain permission from the license holder to reproduce the material. To view a copy of this license, visit http://creativecommons.org/licenses/ by $/ 4.0 /$

(c) The Author(s) 2017

Supplementary Information accompanies this paper on the Nutrition \& Diabetes website (http://www.nature.com/nutd) 